\title{
Electronic medical records and health care promotion in Saudi Arabia
}

\author{
An overview
}

Sana A. AlSadrah, BSMLS, MPH.

\begin{abstract}
منذ عقود قليلة، فعلت الحكومة السعودية السجلات الطبية الإلكترونية في

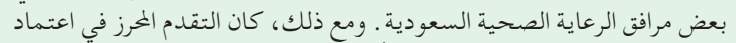

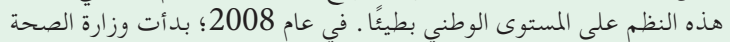

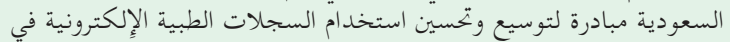

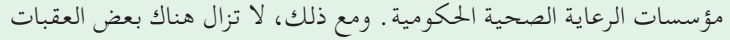

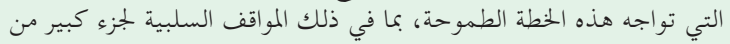

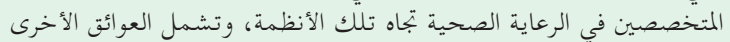

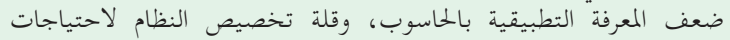

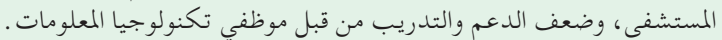

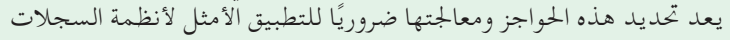

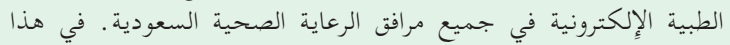

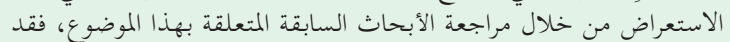

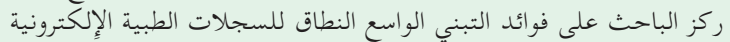

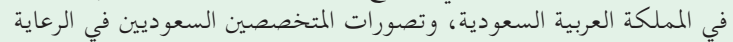

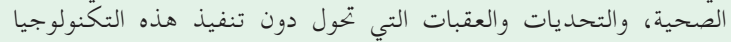
بشكل أفضل.
\end{abstract}

A few decades ago, the government of Saudi Arabia introduced electronic medical records (EMRs) in some health care facilities. However, the progress in adopting these systems on a national level was slow. In 2008, the Saudi Ministry of Health started an initiative to expand and optimize the use of EMRs in governmental health care institutions. However, some obstacles facing this ambitious plan remain, including negative attitudes of some health care professionals toward EMR systems. Other barriers include poor computer literacy, lack of system customization to hospital needs, and poor support and training from information technology (IT) personnel. Identifying and addressing these barriers is essential for the optimal application of EMR systems in all health care facilities. In this review, the author focused on the benefits of widespread adoption of EMRs in Saudi Arabia, the perceptions of health care professionals, and the challenges and barriers toward improved implementation of this technology.
Keywords: electronic medical records, health care, health promotion, primary care; Saudi Arabia

Saudi Med J 2020; Vol. 41 (6): 583-589 doi: 10.15537/smj.2020.6.25115

From the Department of Preventive Medicine, Governmental Hospital Khobar, Ministry of Health, Khobar, Kingdom of Saudi Arabia.

Address correspondence and reprint request to: Mrs. Sana A. AlSadrah, Department of Preventive Medicine, Governmental Hospital Khobar, Ministry of Health, Khobar, Kingdom of Saudi Arabia. E-mail: sana12345.uk@yahoo.com /sana12345.uk@gmail.com ORCID ID: https://orcid.org/0000-0002-1254-3542

$\mathrm{N}$ owadays, the implementation of information technology in the health care system is a must. Hence, medical systems have undergone several changes, including the transition of paper-based medical records to electronic medical records (EMRs). The EMRs are legal records that consist of data concerning patients, such as information about medical history, management plans, and patient reviews. ${ }^{1}$ Further, this EMR data is important for epidemiological studies, clinical trials, drug safety surveillance, and disease registries. ${ }^{2}$

The implementation of EMRs leads to several benefits for patients (elevated quality of health care systems/reduced errors, improved diagnosis, and treatments, faster healthcare decisions) and healthcare workers (increased information exchange among health care workers, decreases in expense and time, and enhancement of the safety culture among primary care providers). ${ }^{3-7}$ Despite general awareness of the importance of electronic health records and related EMRs in the health care industry and the highest increase in usage of electronic health records by health care workers, use of EMRs is still slow in Saudi Arabia, mostly in small and rural hospitals. ${ }^{8,9}$ 


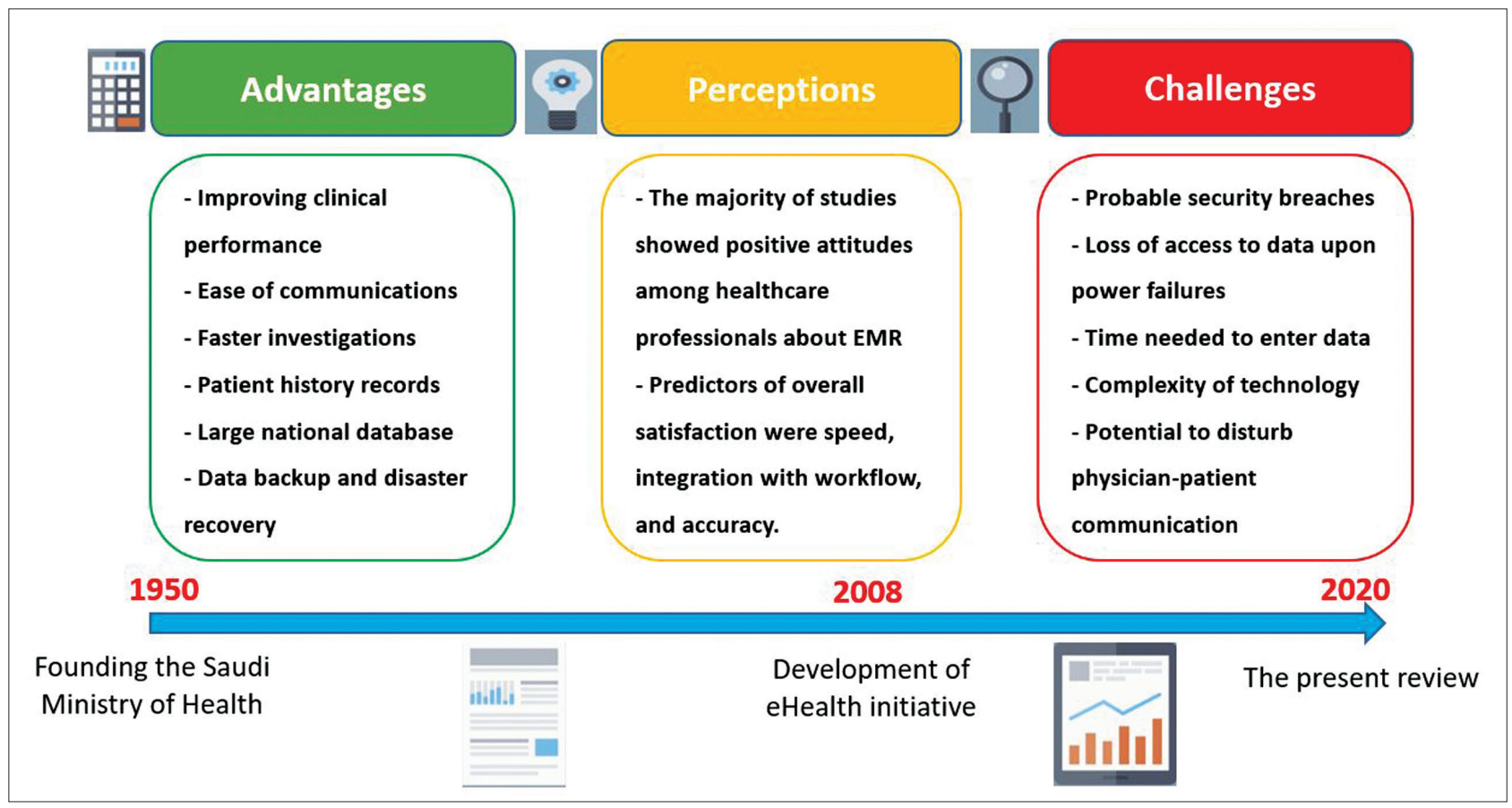

Figure 1 - Summary of the timeline of Electronic Medical Records (EMR) adoption in Saudi Arabia, along with possible advantages and challenges.

In the present review, the author is focused on the benefits of wide-spread adoption of electronic medical records in Saudi Arabia, the perceptions of Saudi health care professionals, and the challenges and barriers toward improved implementation of this technology (Figure 1). The included survey studies on the healthcare professional attitudes towards the EMR have been summarized in Table 1.

The author performed a computerized search of Medline (via PubMed) and Scopus databases up to September 2019, using the following keywords: Electronic medical records OR EMR OR Electronic health records or HER OR computer-based patient record AND Saudi Arabia OR "Kingdom of Saudi Arabia" OR "Mecca" OR "Riyadh" OR "Jeddah". We included all published original studies that assessed the application and utility of EMRs in Saudi Arabia's health system. From each study report, the author extracted data on the study subjects (being surveyed), used questionnaire, sample size, study setting, and findings. The findings of the retrieved studies to synthesize

Disclosure. Author has no conflict of interests, and the work was not supported or funded by any drug company. recommendations as to how to improve EMR utilization in Saudi Arabia was used.

Development and adoption of EMR systems in Saudi Arabia. In 1949, Saudi Arabia established the Ministry of Health $(\mathrm{MOH})$ as the main source of health care in the country. ${ }^{10}$ Since then, approximately $60 \%$ of medical care services in Saudi Arabia have been provided by the $\mathrm{MOH}$; the rest is provided by other governmental organizations and private medical services. Originally, all health records were paper-based, but a few decades ago, some hospitals began to adopt EMR. However, the system lacked widespread application and an integrated national network to link different hospitals (due to strict policies about data sharing between hospitals, lack of highly-trained personnel on the integration of different EMR systems, and lack of cooperation between the public and private health sectors).

In 2008, the government of Saudi Arabia declared the development of eHealth a priority, including moving from paper-based records to EMRs. The mission was to create a safe, quality health care system that prioritizes patient-centric care, enabled by recent health technologies. ${ }^{11}$ Therefore, starting that year (2008), the MOH devoted over 4 billion Saudi riyals (US\$1.07 billion) to eHealth programs. ${ }^{10}$ This budget was allocated to overcome the technical, economic, regulatory, and behavioral barriers against the optimal 
EMRs in Saudi Arabia ... AlSadrah

Table 1 - Summary of the survey studies on healthcare professionals attitudes towards Electronic Medical Records (EMR).

\begin{tabular}{|c|c|c|c|c|c|c|}
\hline $\begin{array}{l}\text { Authors/year } \\
\text { published }\end{array}$ & Subjects & Year & Questionnaire & $\begin{array}{l}\text { Sample } \\
\text { size }\end{array}$ & Study setting & Findings \\
\hline $\begin{array}{l}\text { Shaker et al }{ }^{11} \\
2015\end{array}$ & Physicians & $\begin{array}{c}\text { July to } \\
\text { August } 2009\end{array}$ & $\begin{array}{c}\text { Structured } \\
\text { questionnaire of } \\
15 \text { closed-ended } \\
\text { questions }\end{array}$ & 317 & $\begin{array}{l}\text { Six major hospitals } \\
\text { in Makkah region }\end{array}$ & $\begin{array}{l}\text { Majority of physicians shows } \\
\text { positive response towards } \\
\text { application of EMR systems in } \\
\text { healthcare practice; however, } \\
\text { they reported questions about its } \\
\text { usage easiness and whether it may } \\
\text { disrupt the work flow }\end{array}$ \\
\hline $\begin{array}{l}\text { El-Mahalli }{ }^{14} \\
2015\end{array}$ & Physicians & $\begin{array}{c}\text { February } \\
2012\end{array}$ & $\begin{array}{l}\text { Self-administered } \\
\text { paper-based } \\
\text { questionnaire }\end{array}$ & 319 & $\begin{array}{c}\text { Three governmental } \\
\text { hospitals }\end{array}$ & $\begin{array}{l}\text { Physicians face a lot of barriers } \\
\text { to implement the EMR system } \\
\text { like lack of access to records } \\
\text { upon computer crashes or power } \\
\text { fails, time consumed during } \\
\text { data entry, lack of IT technical } \\
\text { support, complex technology, } \\
\text { and disturbing patient-doctor } \\
\text { communication }\end{array}$ \\
\hline $\begin{array}{l}\text { Aldosari et } \mathrm{al}^{28} \\
2018\end{array}$ & Nurses & $\begin{array}{c}30 \text { April } \\
2013 \text { till } 8 \\
\text { May } 2013\end{array}$ & $\begin{array}{l}\text { Self-administered } \\
\text { questionnaire }\end{array}$ & 153 & $\begin{array}{c}\text { Imam } \\
\text { Abdulrahman } \\
\text { Al Faisal Hospital, } \\
\text { National Guards } \\
\text { Health Affairs, } \\
\text { Dammam, Saudi } \\
\text { Arabia }\end{array}$ & $\begin{array}{l}\text { The results showed a strong } \\
\text { positive correlation between } \\
\text { perceived usefulness and perceived } \\
\text { ease of use and willing to use } \\
\text { EMR to improve the quality of } \\
\text { patient care }\end{array}$ \\
\hline $\begin{array}{l}\text { Almutairi \& } \\
\text { McCrindlel }^{29} \\
2018\end{array}$ & Nurses & NA & $\begin{array}{l}\text { Online } \\
\text { questionnaire with } \\
\text { closed and open } \\
\text { questions }\end{array}$ & 1428 & $\begin{array}{l}\text { MOH's hospitals } \\
\text { in Riyadh and } \\
\text { Jeddah's City }\end{array}$ & $\begin{array}{l}\text { There was a significant relation } \\
\text { between age, gender, nationality } \\
\text { and qualification with the } \\
\text { knowledge or attitude towards } \\
\text { EMR. Most respondents asked for } \\
\text { better qualification in EMR and } \\
\text { health information systems. Other } \\
\text { barriers were linked to technical, } \\
\text { financial and workload issues. }\end{array}$ \\
\hline $\begin{array}{l}\text { Alharthi et } \mathrm{al}^{30} \\
2014\end{array}$ & Physicians & $\begin{array}{c}30 \text { March } \\
\text { and } 25 \text { May } \\
2010\end{array}$ & $\begin{array}{l}\text { Self-administered } \\
\text { survey }\end{array}$ & 115 & $\begin{array}{l}\text { A major } \\
\text { Government } \\
\text { hospital in the } \\
\text { Eastern Province, } \\
\text { Saudi Arabia }\end{array}$ & $\begin{array}{c}\text { The study found that most of } \\
\text { physicians }(60 \%) \text { are not satisfied } \\
\text { with EMR system }\end{array}$ \\
\hline $\begin{array}{l}\text { Hasanin et } \mathrm{al}^{31} \\
2015\end{array}$ & $\begin{array}{c}\text { Healthcare } \\
\text { Professionals } \\
\text { (physicians, nurses, } \\
\text { pharmacists, } \\
\text { receptionists, } \\
\text { laboratory staff, } \\
\text { and administration } \\
\text { staff) }\end{array}$ & $\begin{array}{c}\text { November } \\
2011 \text { and } \\
\text { January } 2012\end{array}$ & $\begin{array}{c}\text { Researcher } \\
\text { developed } \\
\text { quantitative } \\
\text { questionnaire } \\
\text { (online and paper } \\
\text { based) }\end{array}$ & 333 & $\begin{array}{l}\text { Seven Saudi public } \\
\text { hospitals in Jeddah, } \\
\text { Makkah and Taif } \\
\text { cities }\end{array}$ & $\begin{array}{l}\text { The study showed some barriers } \\
\text { that face health care professionals } \\
\text { in the EMR system application } \\
\text { such as poor computer and } \\
\text { English skills }\end{array}$ \\
\hline $\begin{array}{l}\text { Mohamed \& } \\
\text { El-Naif } \\
2005\end{array}$ & $\begin{array}{l}\text { Physicians, nurses } \\
\text { and patients }\end{array}$ & NA & $\begin{array}{l}\text { Self- administered, } \\
\text { pilot-tested, } \\
\text { internally } \\
\text { consistent } \\
\text { questionnaire }\end{array}$ & 334 & $\begin{array}{l}\text { The Military } \\
\text { Hospital in Riyadh }\end{array}$ & $\begin{array}{l}\text { They found physicians generally } \\
\text { not in favor of adoption of EMR } \\
\text { system, in addition, the medical } \\
\text { records are not expected to be } \\
\text { computerized in the near future }\end{array}$ \\
\hline
\end{tabular}

MOH: Ministry of Health, NA: not applicable, 
implementation of EMRs in the health care system. Alongside these efforts, the Saudi Association for Health Informatics was established to coordinate the efforts of this plan. ${ }^{11}$

Despite these efforts, studies continue to show that the implementation of EMRs in Saudi health care institutions remains low. A study by Shaker et $\mathrm{al}^{10}$ has found that among the 36 hospitals in Mecca, only 9 (25\%) achieved comprehensive utilization of all EMR core modules (laboratory, radiology, and pharmacy). This was higher than the percentage recorded in the Eastern province of Saudi Arabia (15.8\%) in 2011. ${ }^{11}$ In 2018 , another study surveyed 15 hospitals in the Eastern province of Saudi Arabia and showed that 7 (46.6\%) had a running EMR system. It also found a wide variation in EMR systems (in terms of operating systems, system features, and security measures), compared to the aforementioned study of Mecca hospitals. ${ }^{12}$ Some authors attributed this slow adoption to some barriers, including lack of experience about using EMR systems, poor computer and English literacy, and staff resistance. ${ }^{13}$ These barriers are discussed in further detail later in this review.

On the bright side, several major health care organizations in the Kingdom of Saudi Arabia achieved major progress in EMR implementation, such as King Faisal Specialist Hospital, National Guard Health Affairs hospitals (which received the Middle East Excellence Award in electronic health records), and Armed Forces hospitals. Of note, these health facilities are not affiliated with the Saudi public hospital system. ${ }^{14}$

Advantages of EMR adoption in Saudi hospitals. The inclusion of EMRs can speed the process of health care delivery at different points of care. For example, they may speed ordering lab tests, radiological investigations, and pharmacy requests. Moreover, they can help with chart review; through EMRs, the nurse/ physician can obtain, review, and store lab/radiology results, scan documents, and review progress notes and correspondence. ${ }^{15}$ They can also create a history for the patient that enables instant identification of his or her comorbidities and past and current medications. ${ }^{16}$ Besides, EMRs can improve the clinical performance of practicing health care professionals by helping with clinical decision making computerized clinical decision support (CCDS). Some of the benefits in this regard include better exposure to updated clinical guidelines, sending alerts upon receiving abnormal test results, and sending drug allergy and interaction alerts. Another useful purpose of implementation is documentation. ${ }^{17}$ An EMR may contain a patient-related medical problem list, a common medication list, patient-specific allergies, and patient discharge instructions. The ease of communication is another major advantage when health care professionals can communicate with patients through email, fax, and phone. ${ }^{18}$

However, published research has shown several shortcomings of EMRs in this regard. For example, an analysis by Holmgren et $\mathrm{al}^{19}$ in the USA reported that EMRs failed to prevent more than one-third of potentially serious medication errors. In a cluster randomized controlled trial in diabetic patients, CCDS did not improve the quality of primary care in comparison to usual care. ${ }^{20}$ Similarly, another study by Kostopoulou et $\mathrm{al}^{21}$ showed similar satisfaction rates between patents whose healthcare providers used CCDS-integrated EMRs and usual EMRs. In the same vein, a systematic review of studies that have assessed the value of CCDS in asthma management concluded that the current CCDS system generations do not provide significant outcome benefits for asthmatic patients. ${ }^{22}$

Based on all these findings, it has been noted that there is a wide gap between health information technology development and the improvements in the quality of delivered healthcare and its outcomes. ${ }^{23}$ Some guidelines were suggested to improve the accuracy of CCDS systems, including using control datasets to verify the accuracy and completeness of patient information, data cleanup strategies, and improving the medical process design. ${ }^{24}$

From a research point of view, turning paper-based data into EMRs confers a huge advantage. Large databases in the USA, such as the Surveillance, Epidemiology, and End Results (SEER), National Inpatient Sample (NIS), and Medicare benefited from nationwide EMR systems with a sample size over millions of patients. This is not only important for clinical investigations, but for evaluating health care policies and informing stakeholders about approaches to improve access to high-quality health care..$^{25}$

Other advantages related to accessibility and management include management and records of patient referrals, allowing health care professionals, even when out of the hospital, to access patient health records, allowing patients to access parts of their health records and providing data backup and disaster recovery. ${ }^{26}$

Knowledge and perceptions of Saudi health care professionals toward EMR. Concerning the usage of EMR benefits, a study by El-Mahalli showed marked underuse of all the functions of EMR that were, most notably, in the data backup and disaster management domains. Similarly, such functions as reviewing progress notes, documenting patients' comorbidities, and using clinical guidelines, had low use frequencies. 
The study highlighted barriers, including lack of access to records upon computer crashes or power failures, time consumed during data entry, lack of IT technical support, complex technology, and disturbing patientdoctor communication. ${ }^{13}$

The perceptions of Saudi health care professionals toward EMR systems have been reported variously across different studies. Shaker et $\mathrm{al}^{10}$ surveyed 307 health care professionals in 6 major hospitals in the Mecca region in 2009. The authors reported generally positive attitudes toward wider adoption of EMR systems in health care practice; however, the participants reported concerns about its ease of use and whether it might disrupt the workflow. In a different study, by Aldosari et al, ${ }^{27} 153$ nurses at the National Guards Health Affairs completed questionnaires about EMR. The results showed a strong positive correlation between perceived usefulness and perceived ease of use and willingness to use EMR to improve the quality of patient care. Almutairi et $\mathrm{al}^{28}$ showed similar results in a sample of 1428 nurses from major governmental hospitals in Riyadh and Jeddah City.

However, in a different study by Alharthi et al, ${ }^{29}$ only $40 \%$ of surveyed physicians in a major governmental hospital were satisfied with the EMR system. The best predictors of overall satisfaction were speed, integration with workflow, and accuracy and completeness of patient data. These points clearly show the value of involving clinicians in the EMR design process. A study by Hasanin et $\mathrm{al}^{30}$ examined the perceptions of Saudi health care professionals toward EMR use and revealed that a lack of computer and English literacy were the main barriers against positive attitudes toward EMR implementation. Mohamed and El-Naif ${ }^{31}$ conducted a survey study among a random sample of physicians and nurses from the military hospital in Riyadh. They found that physicians were generally not enthusiastic about changing to EMRs. Although they highlighted some advantages such as confidentiality, they cited computer illiteracy (only 1\% had good prior computer experience), difficult file organization, and poor training of medical personnel as possible obstacles.

Combined, these studies showed variable attitudes toward adoption of EMR systems, revealed the predictors of EMR acceptance among health care personnel, and highlighted some barriers that we summarize here.

Challenges and barriers. A literature review summarized the barriers to the use of electronic health records (EHRs) by physicians and classified them into 8 main categories. These categories included technical, financial, psychological, social, legal, time, organizational, and change processes. ${ }^{32-36}$ In short, the main highlighted barriers across the eight categories were probable security breaches, loss of access to data upon computer crashes or power failures, the time needed to enter data and check their quality, the complexity of the technology (especially among personnel with poor English language and computer skills), the potential to disturb physician-patient communication, and the lack of system customization for all hospital needs. Other barriers were concerned about the lack of continuous support from IT staff in hospitals and poor training of health care personnel in the use of EMR.

Recommendations. Based on the aforementioned perceptions of health care personnel, expected challenges, and suggestions from prior studies, the author suggest the following recommendations. The training in EMR use should start from the beginning of a health care career; namely, new physicians should receive EMR training during their residency orientation, and this training must continue through subsequent stages of career progression. ${ }^{37}$ This can be achieved through regular conferences, workshops, and online continuing medical education (CME) certificates and cooperation between hospital management and EMR providers to ensure initial and follow-up training. In addition, vendors should provide 24-hour availability of technical support in contracting hospitals. ${ }^{38}$

Another set of recommendations is related to improving the communication between different health care personnel as well as between physicians and their patients. Ensuring the possibility of short message service (SMS) or email communication is a must. This can be achieved by providing quality Internet connection to hospitals and other healthcare delivery facilities, improving patients' awareness about the value of online communication with their health care provider, and increasing physicians' computer literacy. ${ }^{39}$ Physicians should also be able to customize their preferred, easy-to-use EMR interface and should be able to select the optimal tools to achieve effective communications with their patients. ${ }^{40}$

In terms of research and continuous monitoring, hospital management staff should perform periodic assessments of the usage of different EMR functions. Longitudinal studies should monitor health care personnel perceptions about EMR and its ease of use to inform stakeholders about the required needs to ensure full adoption of EMR systems. ${ }^{41}$ These surveys will be of use in a continuous cycle of quality improvement. The retrieved studies were mainly hospital-based; therefore, we could not assess the implementation of EMRs in primary healthcare settings. These settings should be the focus of future studies. In addition, comparative studies 
should compare different EMR systems, not only in terms of accuracy and effectiveness but also regarding health care personnel perceptions about their feasibility and ease of use.

In conclusion, over the few past decades, significant efforts have been exerted to adopt EMR systems in health care facilities in Saudi Arabia. Despite some progress, the current review highlighted some negative perceptions and several barriers toward realizing this goal in full, including poor computer literacy, lack of support from IT staff, and lack of customization to the needs of every hospital system. These obstacles should be addressed on time to ensure optimal applications of EMR systems in Saudi hospitals.

Acknowledgment. The author thanks the Elsevier editing service for providing professional editing for this paper.

\section{References}

1. Zahabi M, Kaber DB, Swangnetr M. Usability and safety in electronic medical records interface design: a review of recent literature and guideline formulation. Hum Factors 2015; 57: 805-834.

2. Ford E, Carroll JA, Smith HE, Scott D, Cassell JA. Extracting information from the text of electronic medical records to improve case detection: a systematic review. J Am Med Inform Assoc 2016; 23: 1007-1015.

3. Edmund LCS, Ramaiah CK, Gulla SP. Electronic medical records management systems: An overview. DESIDOC Journal of Library \& Information Technology 2009; 29: 3-12.

4. Kalogriopoulos NA, Baran J, Nimunkar AJ, Webster JG. Electronic medical record systems for developing countries: review. Conf Proc IEEE Eng Med Biol Soc 2009; 2009: 1730-1733.

5. McGuire MJ, Noronha G, Samal L, Yeh H-C, Crocetti S, Kravet S. Patient safety perceptions of primary care providers after implementation of an electronic medical record system. $J$ Gen Intern Med 2013; 28: 184-192.

6. Chin BJ, Sakuda CMi. Transforming and improving health care through meaningful use of health information technology. Hawaii J Med Public Health 2012; 71 (4 Suppl 1): 50-55.

7. Bates DW, Gawande AA. Improving safety with information technology. N Engl J Med 2003; 348: 2526-2534.

8. Adler-Milstein J, DesRoches CM, Kralovec P, Foster G, Worzala C, Charles D, et al. Electronic health record adoption in US hospitals: progress continues, but challenges persist. Health Aff (Millwood) 2015; 34: 2174-2180.

9. Birkhead GS, Klompas M, Shah NR. Uses of electronic health records for public health surveillance to advance public health. Annu Rev Public Health 2015; 36: 345-359.

10. Sebai ZA, Milaat WA, Al-Zulaibani AA. Health care services in saudi arabia: past, present and future. J Fam Community Med 2001; 8:19-23.

11. Shaker HA, Farooq MU, Dhafar KO. Physicians' perception about electronic medical record system in Makkah Region, Saudi Arabia.Avicenna J Med 2015; 5: 1-5.
12. Bah S, Alharthi H, El Mahalli AA, Jabali A, Al-Qahtani M, Al-kahtani N. Annual survey on the level and extent of usage of electronic health records in government-related hospitals in Eastern Province, Saudi Arabia. Perspect Health Inf Manag 2011; 8: 1b.

13. Jabali K, Jarrar Mt. Electronic health records functionalities in Saudi Arabia: Obstacles and major challenges. Global Journal of Health Science 2018; 10: 50.

14. El Mahalli AA. Electronic health records: Use and barriers among physicians in eastern province of Saudi Arabia. Saudi Journal for Health Sciences 2015; 4: 32.

15. Qurban MH, Austria R. Public perception on e-health services: Implications of prelimary findings of KFMMC for military hospitals in KSA. Proceedings of the European and Mediterranean Conference on Information Systems, EMCIS 2008.

16. King J, Patel V, Jamoom EW, Furukawa MF. Clinical benefits of electronic health record use: national findings. Health Serv Res 2014; 49 (1 pt 2): 392-404.

17. Hillestad R, Bigelow J, Bower A, Girosi F, Meili R, Scoville R, et al. Can electronic medical record systems transform health care? Potential health benefits, savings, and costs. Health Aff (Millwood) 2005; 24: 1103-1117.

18. Menachemi N, Collum TH. Benefits and drawbacks of electronic health record systems. Risk Manag Healthc Policy 2011; 4: 47.

19. Sujansky WV. The benefits and challenges of an electronic medical record: much more than a" word-processed" patient chart. West J Med 1998; 169: 176.

20. Holmgren AJ, Newmark L, Danforth M, Classen D, Bates D. Assessing the safety of electronic health records: a national longitudinal study of medication-related decision support. $B M J$ Qual Saf 2020; 29: 52-59.

21. Heselmans A, Delvaux N, Laenen A, Van de Velde S, Ramaekers D, Kunnamo I, et al. Computerized clinical decision support system for diabetes in primary care does not improve quality of care: a cluster-randomized controlled trial. Implement Sci 2020; 15: 1-14.

22. Kostopoulou O, Porat T, Corrigan D, Mahmoud S, Delaney BC. Diagnostic accuracy of GPs when using an early-intervention decision support system: a high-fidelity simulation. $\mathrm{Br} J$ Gen Pract 2017; 67: e201-e208.

23. Matui P, Wyatt JC, Pinnock H, Sheikh A, McLean S. Computer decision support systems for asthma: a systematic review. NPJ Prim Care Respir Med 2014; 24: 1-10.

24. Sheikh A. Realising the potential of health information technology to enhance medication safety. BMJ Qual Saf 2020; 29: 7-9.

25. Hasan S, Padman R. Analyzing the effect of data quality on the accuracy of clinical decision support systems: a computer simulation approach. AMIA Annu Symp Proc 2006: 324-328.

26. Thompson DI, Osheroff J, Classen D, Sittig DF. A review of methods to estimate the benefits of electronic medical records in hospitals and the need for a national benefits database. $J$ Healthc Inf Manag 2007; 21: 62-68.

27. Podichetty V, Penn D. The progressive roles of electronic medicine: benefits, concerns, and costs. Am J Med Sci 2004; 328: 94-99.

28. Aldosari B, Al-Mansour S, Aldosari H, Alanazi A. Assessment of factors influencing nurses acceptance of electronic medical record in a Saudi Arabia hospital. Informatics in Medicine Unlocked 2018; 10: 82-88. 
29. Almutairi A, McCrindlel R. A case study of nurses perceptions and attitude of electronic medical records in Riyadh and Jeddah's Hospitals. Health Informatics and Medical Systems 2018; 16.

30. Alharthi H, Youssef A, Radwan S, Al-Muallim S, Zainab A-T. Physician satisfaction with electronic medical records in a major Saudi Government hospital. Journal of Taibah University Medical Sciences 2014; 9: 213-218.

31. Hasanain RA, Vallmuur K, Clark M. Electronic medical record systems in Saudi Arabia: knowledge and preferences of healthcare professionals. Journal of Health Informatics in Developing Countries 2015; 9: (1).

32. Mohamed BA, El-Naif M. Physicians', nurses' and patients' perception with hospital medical records at a military hospital in riyadh, saudi arabia. J Family Community Med 2005; 12: 49-53.

33. Ajami S, Bagheri-Tadi T. Barriers for adopting electronic health records (EHRs) by physicians. Acta Inform Med 2013; 21: 129.

34. Kunz MK. Helping nurses overcome possible barriers. Nurs Womens Health 2010; 14: 290-300.

35. Loomis GA, Ries JS, Saywell RM, Thakker NR. If electronic medical records are so great, why aren't family physicians using them? J Fam Pract 2002; 51: 636-641.

36. Likourezos A, Chalfin DB, Murphy DG, Sommer B, Darcy K, Davidson SJ. Physician and nurse satisfaction with an electronic medical record system. J Emerg Med 2004; 27: 419-424.
37. Sittig DF, Kuperman GJ, Fiskio J, editors. Evaluating physician satisfaction regarding user interactions with an electronic medical record system. Proc AMIA Symp 1999: 400-404.

38. Wiljer D, Urowitz S, Apatu E, DeLenardo C, Eysenbach G, Harth T, et al. Patient accessible electronic health records: exploring recommendations for successful implementation strategies. J Med Internet Res 2008; 10: e34.

39. Goetz DG, Kuzel AJ, Feng LB, DeShazo JP, Love LE. EHRs in primary care practices: benefits, challenges, and successful strategies. Am J Manag Care 2012; 18: e48-e54.

40. Shoolin J. Change management-recommendations for successful electronic medical records implementation. Appl Clin Inform 2010; 1: 286-292.

41. Middleton B, Bloomrosen M, Dente MA, Hashmat B, Koppel R, Overhage JM, et al. Enhancing patient safety and quality of care by improving the usability of electronic health record systems: recommendations from AMIA. J Am Med Inform Assoc 2013; 20: e2-e8.

42. Hameed SA, Mustapha S, Mardhiyah A, Miho V, editors. Electronic medical record for effective patient monitoring database. Kuala Lumpur (Malaysia): 2008 International Conference on Computer and Communication Engineering; 2008. 